\title{
Os sentidos da prática: o que fazemos quando dizemos que filosofamos com crianças
}

The meanings of practice: what we do when we say we philosophy with children

Mauro Britto Cunha Jair Miranda de Paiva

Resumo: No presente texto busca-se problematizar o fazer filosófico com crianças, colocando especial atenção ao nosso fazer filosófico com crianças no município de São Mateus, problematizando suas relações, implicações e sentidos. Parte-se de questões como: o que fazemos/praticamos quando afirmamos que estamos experimentando pensamentos filosóficos com crianças? É possível falar de uma identidade do fazer filosófico com crianças na rede municipal de educação de São Mateus? Quais propósitos estão em questão no exercício dessa prática? Para situar tais questionamentos, busca-se elementos na perspectiva histórica do filosofar no município, que possam ajudar a compor um quadro mais amplo dos sentidos que esse fazer nos provoca. Percebendo por meio dos relatos dos educadores/as a força da chamada "postura filosófica" nesse movimento, compreendo que a experiência do filosofar não se esgota em apenas entender, analisar, interpretar o mundo, os fatos, as relações, mas, sobretudo, em criar novos mundos, outros fatos, diferentes relações. Criando novas organizações no pensamento, capazes de transformar, de ressignificar, de "desengaiolar" as ideias. Acreditamos que as ideias aqui trabalhadas são capazes de nos encetar perspectivas que podem, em alguma medida, contribuir com o fazer filosófico junto aos mais pequeninos e, principalmente, apontar elementos que possam dar sentido ao que se experimenta quando se diz que o que se pratica é filosofia com crianças. Em última instância, entendemos que filosofar com crianças não deve configurar-se em um querer transformar a criança naquilo que ela não é, nem em transformar a filosofia em instrumento de cerceamento do pensamento da infância. Esse movimento tem a ver com abertura ao novo. Novidade que a criança carrega e que a filosofia se nutre. Uma interação entre adultos e crianças, através da abertura ao diálogo fraterno e solidário.

Palavras-chave: Filosofia. Infância. Experiência. Ensino.

Abstract: In this text we seek to problematize the philosophical doing with children, placing special attention on our philosophical doing with children in the city of São Mateus, problematizing their relationships, implications and meanings. It starts with questions like: what do we do / practice when we say that we are experiencing philosophical thoughts with children? Is it possible to speak of an identity of doing philosophical work with children in the municipal education network of São Mateus? What purposes are at issue in the exercise of this practice? In order to situate such questions, we seek elements in the historical perspective of philosophizing in the municipality, which can help to compose a broader picture of the meanings that doing this causes us. Realizing through the educators' reports the strength of the so-called "philosophical posture" in this movement, I understand that the experience of philosophizing is not limited to just understanding, analyzing, interpreting the world, the facts, the relationships, but, above all, in create new worlds, other facts, different relationships. Creating new organizations in thought, capable of transforming, reframing, "untangling" ideas. We believe that the ideas worked on here are capable of giving us 
perspectives that can, to some extent, contribute to making philosophical work with the little ones and, above all, pointing out elements that can give meaning to what is experienced when it is said that what is practiced it's philosophy with children. Ultimately, we understand that philosophizing with children should not be configured in wanting to transform the child into what he is not, nor in transforming philosophy into an instrument of curbing childhood thinking. This movement has to do with opening up to the new. Novelty that the child carries and that philosophy nourishes. An interaction between adults and children, through openness to fraternal and solidary dialogue.

Keywords: Philosophy. Childhood. Experience. Teaching.

\section{Introdução}

Nos colocamos aqui a pensar nossa relação com a filosofia e a infância. Buscando lançar cuidadosa atenção ao nosso fazer filosófico com crianças no município de São Mateus.

Organizamos esta escrita da seguinte forma: num primeiro momento, destacamos algumas questões que nos provocam em relação ao movimento de filosofia que desenvolvemos a partir de nossa atuação docente ${ }^{1}$; em seguida, deslocamos nosso olhar para alguns pressupostos fundamentais que compõem a construção de uma narrativa histórica, pois, entender os atuais movimentos filosóficos com crianças em São Mateus demanda situar, ao menos, parte da trajetória desse percurso; na sequência, apresentamos fragmentos históricos referentes à trajetória, construção, e implantação da filosofia na educação do município, bem como alguns dos sentidos provocados por esta inserção. Por fim, apontamos pistas acerca do saber/fazer filosófico com crianças que podem nos ajudar a compreender o sentido do que praticamos ou desejamos praticar enquanto potência filosófica com as crianças, destacando a força da criação e da pergunta contida no cerne da filosofia e da infância.

\section{Perguntas que nos desassossegam}

Afirmar que se ensina filosofia, ou que, ao contrário, se ensina a filosofar, em alguma medida, implica estar situado em um problema filosófico. Afinal, não

\footnotetext{
${ }^{1}$ As ideias principais deste artigo se inspiram na dissertação por nós defendida no Programa de Pós-graduação em Ensino na Educação Básica, no Ceunes, UFES, São Mateus, em 2018, intitulada: "Em busca da infância: experiências filosóficas com crianças numa escola pública municipal de São Mateus, ES".
} 
deveria todo ensino de filosofia, desde o princípio, já ser uma experiência do filosofar? Pensamos com Alejandro Cerletti (2009, p.19) que "[...] ensinar filosofia e ensinar a filosofar conformam uma mesma tarefa de desdobramento filosófico, em que professores e alunos compõem um mesmo espaço comum de pensamento".

Esta compreensão nos faz perceber outras perguntas que desenham e atravessam as práticas filosóficas na escola, a saber: o que se entende por experimentar pensamentos filosóficos? Que caminho ou estratégia é preciso percorrer para vivenciar tal experiência? É possível transferir uma experiência filosófica?

Situando nossa atenção aos movimentos filosóficos praticados com crianças nas escolas públicas municipais de São Mateus, ES, estas provocações nos suscitam indagar: o que fazemos/praticamos quando afirmamos que estamos experimentando pensamentos filosóficos com crianças? É possível falar de uma identidade do fazer filosófico com crianças na rede municipal de educação de São Mateus? Quais propósitos estão em questão no exercício dessa prática?

Desde já, salientamos que este escrito não busca dar respostas aos desafios e inquietações apresentadas em relação às práticas de filosofia com criança na rede municipal de educação de São Mateus, mas, sobretudo, pretende ser um exercício cuidadoso de lançar o olhar sobre questões que afetam diretamente ou indiretamente esse movimento, seu processo de construção e seus respectivos sentidos. Construir pistas que potencializem a reflexão em torno dessa problemática é o nosso intuito.

Alejandro Cerletti $(2009$, p. 20) nos lembra que "não se pode ensinar filosofia 'desde lugar nenhum', com uma aparente assepsia ou neutralidade filosófica. Sempre se assume e se parte, explícita ou implicitamente, de certas perspectivas [...]". E, Dermeval Saviani (2013, p. 155), nos alerta: “[...] os problemas educacionais não podem ser compreendidos a não ser na medida em que são referidos ao contexto em que se situam". Com base nessas concepções, compreendemos que, para refletirmos acerca dos movimentos filosóficos com crianças na rede municipal de educação de São Mateus, será necessário atentar 
a seus processos de invenção, implantação e construção históricas que acontecem há mais de 20 anos. Pois, as indagações postas têm relação direta com acontecimentos do presente e com seus processos de criação.

É importante salientar que ao nos colocarmos diante dos desafios das perguntas suscitadas, inevitavelmente, também nos colocamos em questão, colocamos nossa própria subjetividade como objeto de pesquisa, já que, como destaca Kohan:

Qual o sentido do perguntar em filosofia? Talvez como em nenhum outro saber, as perguntas filosóficas têm o sentido de um perguntar-se, de colocar a própria subjetividade em questão. O seu sentido principal não é encontrar um saber 'externo' ao sujeito da pergunta. Tal sentido se desdobra na pergunta, num compromisso vital com a interrogação que a pergunta coloca, no próprio movimento do pensar que ela provoca. Por isso, em filosofia é impossível perguntar no lugar do outro, fazer perguntas pelo outro. Precisamos para isso ser esse outro [...] (KOHAN, 2011, p. 104, grifo nosso).

Com base no exposto, somos convidados a pensar a construção de nossas práticas docentes, dos sentidos que atravessam o nosso fazer filosófico com crianças, nos colocando enquanto parte de um fazer sempre em construção, numa postura de abertura às possibilidades que a infância pode nos apresentar. Afinal, trabalhar com o pensamento é estar diante de infinitas e inimagináveis maneiras de criação, e pensar com as crianças é viver aventuras e experiências que possuem a força de nos deslocar, de nos tirar de lugares comuns, desconstruindo padrões de pensamentos e abrindo horizontes ainda não explorados.

\section{A infância da memória}

Mais à frente, apresentaremos fragmentos históricos referentes à trajetória e à implantação da filosofia na educação municipal de São Mateus, e para isso, tomaremos como base informações da pesquisa de Cunha (2018), intitulada: "Em busca da infância: experiências filosóficas com crianças numa escola pública municipal de São Mateus, ES”, pois, essa foi a primeira pesquisa a tecer, a costurar fragmentos históricos sobre o assunto numa perspectiva 
infantil da construção historiográfica. Porém, vale ressaltar que essa não é a única pesquisa a colocar atenção no assunto, há também a importante pesquisa de Jesus (2018) intitulada: "Sophia mora ao lado: Avanços e Entraves do Ensino de Filosofia na Rede Municipal de São Mateus - São Mateus/ES”, que também trouxe importantes reflexões à temática.

Antes de explorarmos as narrativas históricas propriamente ditas, e levando em conta que possuem como principal matéria-prima de sua construção a memória dos indivíduos participantes, faremos algumas considerações, visando situar o leitor em relação às peculiaridades da produção histórica fundada na memória, uma vez que, esta se movimenta, se transforma, se confunde, se esquece, se reinventa.

Segundo Marc Bloch (2001), resguardar a poesia enquanto parte integrante da composição histórica é fundamental, porque as narrativas são atravessadas por sentidos do vivido, do acontecido que, ao serem rememoradas, recontadas, são atualizadas pelo presente e ganham novos significados, uma vez que, o homem é produto das transformações constantes do tempo, e esse movimento possibilita transformações em seus pensamentos e memórias. Segundo ele, este processo não diminui a importância dos fatos narrados, ao contrário, ele atualiza e enche de sentido a experiência da narração, por isso, o enfático conselho:

Resguardemo-nos de retirar de nossa ciência sua parte de poesia. Resguardemo-nos sobretudo, já surpreendi essa sensação em alguns, de enrubescer por isso. Seria uma espantosa tolice acreditar que, por exercer sobre a sensibilidade um apelo tão poderoso, ela devesse ser menos capaz de satisfazer também nossa inteligência (BLOCH, 2001, p. 44, grifo nosso).

Compreende-se que a memória atual dos participantes que ajudaram a tecer uma narrativa acerca da história da filosofia com crianças no município de São Mateus, não são exatamente as mesmas memórias de anos atrás, visto que as pessoas mudam, e com elas, suas memórias; por isso, pressupomos que alguns eventos narrados podem ter sido esquecidos, outros confundidos, e porque não, alguns até inventados/criados. Com base nessa perspectiva da 
sempre atual memória, fica evidente a condição infantil da memória, memóriainfante.

Neste sentido, Walter Omar Kohan (2007) nos apresenta uma concepção de infância intensa, potente, que pode ser vivida a qualquer tempo/época, uma infância que se movimenta pela vida, sendo condição da própria existência humana e de qualquer experiência de pensamento possível. A partir disso, podemos falar em um narrar-infante, ou seja, o exercício sempre novo/atualizado de contar, narrar, construir, inventar histórias.

Ser infante é estar diante do novo, é vivenciar o novo sempre mais uma vez. E narrar a partir da memória, do ato de rememorar, é sempre uma experiência de criação. É uma arte única, que se refaz a cada novo esforço de se lembrar dos acontecidos a serem contados. É sempre uma nova experiência infantil da memória.

Como é possível perceber, o exercício de narrar resgata a memória para infinitos encontros e composições, por isso, o contar é uma arte do fazer, do produzir, do transformar uma realidade que existe em função do que outrora foi falado/vivido. Mesmo que ao narrar o indivíduo não perceba, não se dê conta, a história contada é sempre atual, porque o sujeito será sempre outro, transformado, alterado, infantil. Sobre essa perspectiva de entendimento característico da memória nos diz Certeau:

Talvez, a memória seja, aliás, apenas essa 'rememoração', ou chamamento pelo outro, cuja impressão se traçaria como em sobrecarga sobre um corpo há muito tempo alterado jamais sem o saber. Esta escritura originária e secreta 'sairia' aos poucos, onde fosse atingida pelos toques. [...] é tocada pelas circunstâncias, como o piano que produz sons aos toques das mãos (CERTEAU, 1998, p. 163, grifo nosso).

É importante salientarmos que não trabalhamos com a hipótese da 'verdade histórica absoluta' acerca dos fatos narrados, mas temos clareza de termos optado por uma ótica de "amarração" dos relatos, reconhecendo que há outros prismas de abordagens e composições possíveis. Sabermos da fragilidade da memória quando se trata de legitimação dos acontecimentos históricos. Por isso, damos maior atenção aos sentidos atribuídos aos 
acontecimentos por aqueles que os narram, ou seja, nas histórias contadas nos importam mais a relação entre os fatos narrados e os significados construídos por aqueles que os contam.

Dessa forma, acreditamos que narrar história é fazer política, afinal, como salienta Cardoso (2008, p. 9), "[...] é necessário reconstruir o passado, não para buscar o que aconteceu, mas para entender o mundo que se descortina a partir dali”. É buscar compreender quais movimentos, ações e caminhos foram traçados enquanto ecos que repercutiram e reverberaram dos acontecimentos e experiências vividas.

Enfim, compor histórias é uma arte do fazer, do construir e reconstruir o cotidiano. É contar-se por meio das 'memórias inventadas' como o fez Manoel de Barros (2000). É um exercício infinito de carregar "água na peneira". É contar um fato sempre com ar de novidade, experimentando a infância da memória e ressignificando os sentidos do vivido.

\section{Filosofia com crianças em São Mateus}

O programa de filosofia para crianças chegou ao município de São Mateus em meados dos anos 90, por iniciativa do Centro Educacional "São Gotardo", mais conhecido como "Colégio Conhecer", uma instituição da rede privada de ensino que, em busca de inovação e de uma educação mais voltada ao trabalho das questões humanas, viu nesse programa uma ferramenta pedagógica, inserindo-o em seu currículo no ano de 1994. Nesse período a escola trouxe o treinamento oferecido pelo Centro Brasileiro de Filosofia para Crianças (CBFC), proporcionando que toda a sua equipe de profissionais participasse daquela formação².

\footnotetext{
${ }^{2}$ Quando construímos este histórico não havia nenhum documento oficial escrito que narrasse a trajetória da filosofia com Crianças na Rede Pública de Ensino de São Mateus, até onde pesquisamos (Secretaria Municipal de Educação, Conselho Municipal de Educação, contatos com professores mais antigos da Rede). A nossa narração histórica foi produzida com base em três movimentos distintos, mas conectados entre si. Primeiro: nas informações produzidas num encontro inicial e numa entrevista feita com a professora Dena (2017), moradora de São Mateus e já aposentada; segundo: nas entrevistas realizadas com (três) pedagogos em exercício, (quatro) professores de filosofia em exercício e (três) ex-professores de filosofia; terceiro: a partir das informações disponibilizadas pela Secretaria Municipal de Educação de São Mateus durante o Curso de Formação Continuada em Filosofia para Crianças nos anos de 2016/2017, em uma parceria entre a Prefeitura de São Mateus e o Centro Universitário Norte do Espírito Santo, e também com base nas informações produzidas através da comissão de estudos da disciplina de
} 
A professora Dena ${ }^{3}$ (2017), funcionária desse colégio durante o período, participou da mencionada formação, com os demais companheiros de trabalho. Posteriormente também cursou todos os módulos do programa Filosofia para Crianças (doravante $\mathrm{FpC}$ ), exceto o módulo voltado para o trabalho com o ensino médio.

Segue relato da professora Dena (2017) acerca desse movimento que o colégio fez de aproximação e, posteriormente, adesão ao programa FpC:

A diretora da época [...] sempre buscou coisas bacanas que pudesse agregar à proposta de ensino da escola e fazer uma educação mais para humanidades, então nessa época eles souberam do Centro Brasileiro de Filosofia. Não sei precisamente se foi em 1992 ou 1993, mas eles estiveram em Brasília no evento de educação, onde conheceram essa proposta, onde eles conheceram o Lipman. Eu conheci a proposta de filosofia para crianças em 1994, a escola em que eu trabalhava [Colégio Conhecer] inseriu no currículo da escola, que era uma escola particular, então toda equipe também participou dos treinamentos do Centro Brasileiro de Filosofia. Eles trouxeram até a escola e todos nós passamos por aquele treinamento. A partir daí eu comecei a trabalhar na minha turma que na época era segunda série, não, era primeira série (PROFESSORA DENA, 2017).

No ano de 1998, a professora Dena (2017) foi convidada a trabalhar como Coordenadora da Educação Infantil do Município de São Mateus, sendo que naquela ocasião a Educação Infantil municipal era gerenciada pela Associação de Moradores Nova Esperança4, na pessoa da Sr. ${ }^{a}$ Luigia Bordoni. No ano

\footnotetext{
filosofia do Conselho Municipal de Educação de São Mateus, do qual o pesquisador/autor fazia parte naquela ocasião, como um dos relatores do parecer sobre 'O Ensino de Filosofia Para e Com Crianças em São Mateus'.

${ }^{3}$ É importante destacar que todos os entrevistados e entrevistadas aparecem no texto com o nome fictício, exceto professora "Dena", que nos solicitou fosse mantida a menção a seu nome (trata-se de um apelido o que, em parte, atende à dimensão ética da confidencialidade).

${ }^{4}$ A Associação de Moradores 'Nova Esperança' foi criada em $1^{\circ}$ de outubro de 1970 pelo casal de missionários italianos, Egídio e Luigia Bordoni. Criada para oferecer apoio a famílias de bairros carentes de São Mateus, através da ajuda mútua, a Associação Nova Esperança centrou o foco da sua ação em crianças e adolescentes, através principalmente da educação. Em fevereiro de 1972 foi fundada uma Escola Estadual de Ensino Fundamental e em 1974 um Centro de Educação Infantil (CEIM). A partir de 2013, devido a mudanças na legislação, a coordenação dos centros de ensino foi passada para a Prefeitura e para o Governo do Estado, continuando a parceria para manter o nível do ensino em patamares de excelência. Em 2016 começaram atividades de formação profissionais com os pais e em 2017 atividades de cunho esportivo e
} 
seguinte, a professora Dena (2017) deixou a coordenação da Educação Infantil municipal e passou a dedicar-se à Coordenação do espaço interno da Associação. E foi nesse ano que as práticas de filosofia com crianças começaram a ser desenvolvidas na educação pública do município, por iniciativa da professora Dena, e com o aval da Sr. ${ }^{a}$ Luigia Bordoni. A esse respeito, a Professora Dena (2017) nos relata:

Foi neste ano em que a filosofia com crianças nasceu, em 1999 [na rede pública de São Mateus], porque eu deixei de fazer a coordenação lá fora, e vim fazer a coordenação aqui dentro. Então eu não coordenava a escola e nem coordenava a educação infantil, eu fiquei como se fosse aquele coordenador que vai ver quais são as necessidades da escola e vai atuar naquele perfil, naquela demanda. Então a demanda daquele ano foi trabalhar o sentimento de pertença (PROFESSORA DENA, 2017, grifo nosso).

Muitas crianças que estudavam nos espaços escolares situados na associação de moradores não reconheciam aquele ambiente como sendo delas, da comunidade da qual eram oriundas, por isso, segundo a entrevistada, com frequência "sabotavam" regras, chegando até a cometerem atos de depredação da estrutura física e de materiais.

Diante da situação posta, a professora Dena (2017) resolveu inserir a filosofia com crianças nas atividades dos pequeninos, com objetivo de trabalhar a consciência de pertença àquele espaço através da reflexão em torno do cuidado com o espaço como cuidado de si e dos outros. Pois, aquele ambiente havia sido construído com muito esforço e participação da comunidade local, e que estava a serviço de cada um deles, pertencendo a todos.

Deve-se registrar que os alunos da educação infantil da associação ficavam em tempo integral, já os do ensino fundamental I estudavam meio

culturais com adolescentes e jovens. Nova Esperança oferece educação de qualidade a centenas de crianças e adolescentes de São Mateus, em diálogo e colaboração com suas famílias. Um trabalho que nasce da crença de que a educação é, por excelência, um meio de construção e de expressão da verdadeira cidadania. Nova Esperança, "além dos trabalhos interdisciplinares e contextualizados, transmite aos alunos, da educação infantil ao ensino fundamental ( $1^{a}$ a $4^{a}$ séries), uma visão de conhecimento voltada para a construção a partir do 'eu' de cada criança e adolescente, através da educação musical, hortifruticultura, informática, trabalhos manuais, esporte, acompanhamento escolar e filosofia". Disponível em: <http://www.novaesperanca.org.br/>. Acesso em: 21/02/2021. 
período. Esses últimos, juntamente com aqueles alunos concludentes, os que já estavam estudando no ensino fundamental II em outra unidade de ensino, realizavam atividades na associação no contraturno de seu horário de aula. Era nesse espaço de tempo que a filosofia, juntamente com outras atividades, passou a ser ofertada para as crianças.

Vale lembrar que, segundo a perspectiva da professora Dena (2017), o trabalho feito com as crianças a partir da filosofia, não se mostraria tão potente caso ficasse restrito apenas a uma sessão filosófica por semana, não sendo exercitado em outros momentos. Por isso, a professora decidiu ampliar essa experiência para todos os profissionais da escola, sendo um modo de estimular cada um dos professores e tutores, a desenvolver uma postura filosófica em seu trabalho com as crianças. Não que eles fossem trabalhar filosofia com as crianças, mas que, em suas ações pedagógicas, tornassem intrínseca uma postura atenta, provocadora e inquieta, fundada na observação e na escuta, postura que potencializa a capacidade reflexiva das crianças. Acerca dessa extensão da atividade formativa aos profissionais da associação, a professora Dena (2017) nos diz:

E para que as crianças pudessem ser conduzidas de uma forma reflexiva, eu percebi a necessidade de trabalhar as questões filosóficas com eles. Então todos os tutores e professores tinham um momento na semana que sentavam com a gente, e a gente ia tratar de temas ligados a proposta de Lipman, mas com maior margem de liberdade para outros campos. De uma certa forma, o que eu fazia: eu pegava a estrutura de diálogo que tem muito claro dentro da proposta do Lipman, da Comunidade de Investigação, e tentava montar dentro dos textos que a gente utilizava, porque com a equipe, eu não utilizava as novelas. [...] Eu tentava dentro dos textos ou dentro das conversas trazer algumas coisas que quisessem debater. Eles iam trabalhar a postura. Por que que eu creio nisso? Se você não tem uma postura filosófica, você pode pegar uma novela do Lipman, você pode pegar um texto bacana, que você não vai fazer um debate filosófico. Se a sua postura não for de escuta, você não vai conseguir trabalhar a ideia do outro (PROFESSORA DENA, 2017, grifo nosso). 
O trabalho realizado no interior da Associação Nova Esperança vai, aos poucos, produzindo laços de convivência, e o sentimento de pertença. Até uma reunião/formação mensal com os diretores dos Centros de Educação Infantil Municipais (CEIM's) é organizada na associação, com objetivo de realizar estudos em torno desse programa. Com isso, a proposta da filosofia com crianças vai se firmando e o movimento ao seu redor se expandido.

Em 2004, é construída a Proposta Pedagógica da Educação Infantil do município de São Mateus. "Escrita a 300 mãos", como foi chamada, por professores e diretores dos CEIM's, esta proposta contemplou espaço para a filosofia, mas não exatamente enquanto disciplina, e sim enquanto uma postura filosófica do professor na sua prática pedagógica, a mesma perspectiva da professora Dena na instrução aos professores e tutores que trabalhavam no espaço da Associação Nova Esperança.

Nessa época, professores da rede municipal que atuavam em outros CEIM's começaram a aventurar-se em desenvolver as práticas filosóficas com as crianças, inspirados na iniciativa de Nova Esperança. Uma dessas professoras foi Andressa. Atualmente pedagoga. Na época, ela travou contato com a filosofia, passando, segundo ela, por uma experiência transformadora a partir desse encontro, modificando sua forma de lidar com as crianças, tendo um olhar mais cuidadoso, mudando por completo a relação consigo e com os outros, impulsionada pela nova forma de pensar.

E o trabalho de formação dos professores em torno dessa prática continuava a ser desenvolvido pela professora Dena. Após ficar cerca de 04 anos atuando como coordenadora interna na Associação Nova Esperança, ela retorna à coordenação pedagógica da educação infantil do município, e encontra muita dificuldade para desenvolver os treinamentos, principalmente porque os professores não tinham tempo reservado ao planejamento pedagógico. Contudo, Dena vai rompendo os desafios, juntamente com outros profissionais que abraçaram a proposta e, a passos lentos, porém, contínuos, vão sustentando o movimento da filosofia com crianças na educação pública do município. A professora Dena (2017) relata que: 
Era um trabalho muito penoso, tá, não pensa que era fácil não. Era eu como coordenadora pedagógica de 34 CEIM's, não tinha pedagogas nos CEIM's, era eu quem fazia esse trabalho. Eu dividia os CEIM's em blocos. [...] E daí eu fazia uma formação com eles. Naquela época o planejamento não existia. E professores da Educação Infantil não tinham direito ao planejamento. Separava uma vez por mês, durante o dia inteiro, e nisso cada professor no seu turno, e quem tinha 50 horas parava o dia inteiro para estudar (PROFESSORA DENA, 2017, grifo nosso).

Inspirados pela proposta de $\mathrm{FpC}$, um grupo pequeno de professores já tinham se aventurado a ir a São Paulo no Centro Brasileiro de Filosofia para Crianças fazer treinamento. Todavia, a demanda por formação era cada vez maior no município. Diante disso, cerca de 50 professores, no ano de 2005, se uniram e, com recursos próprios, trouxeram um grupo de formadores do CBFC para dar um curso intensivo em São Mateus. Essa formação aconteceu nas dependências da Associação de Moradores Nova Esperança.

Todo mundo começou a querer, todo mundo começou a querer. [Diziam:] Dena, vamos trazer alguma coisa! E não mais queriam ir a São Paulo. Queriam que eu trouxesse, então sabe o que a gente fez? A gente pegou o nosso dinheirinho, nosso rico dinheirinho, suadinho, suadinho, suadinho... Dividiu o valor que eles iam nos cobrar entre as primeiras cinquenta pessoas que queriam fazer o curso, e trouxemos para São Mateus. Nós trouxemos e aqui em Nova Esperança nós promovemos esse encontro de uma semana (PROFESSORA DENA, 2017, grifo nosso).

Com o passar do tempo, os textos do Lipman foram sendo deixados de lado na formação com os professores, pois, a Professora Dena (2017) passou a compreender que as questões apresentadas por ele já não tinham tanta relevância para a realidade mateense. Além do mais, o município carecia de recursos para adquirir tais materiais. No entanto, ela destaca que no início de sua formação, esses recursos pedagógicos foram essenciais.

Eu comecei a entender isso, que Lipman era para aquela estrutura que poderia comprar os materiais, e o município não ia dar conta. Nova Esperança comprou os materiais, mas logo foi deixado de lado, porque ele não fazia parte 
das nossas questões, das nossas demandas. Lá tem assuntos muitos bacanas e temas muito bacanas que a gente pode utilizar, se essa demanda acontecer, de debate. Apesar de que eu acho que a estrutura que eu tive no início me serviu muito, foi a minha academia (PROFESSORA DENA, 2017).

A forma como os professores fizeram para trazer até são Mateus o CBFC deixa evidente que a inserção da filosofia no município foi/é um movimento em que se mesclou, a nosso ver, a busca de algo novo para a educação, demonstrando que havia um entusiasmo muito forte, heroísmo, abnegação e persistência. Por isso, apesar dos entraves, a iniciativa seguiu conquistando espaço, mesmo que para isso, tivessem sido utilizados caminhos alternativos, improvisados, ou como nos relata a professora Dena (2017): "tudo muito doido".

Então esses 50 professores participaram desse evento. E aí esses 50 professores começaram a pipocar em todos os CEIM's. E começou a pipocar gente de todo lado querendo trabalhar, querendo conhecer, e aí o que a gente fazia? A gente fazia um arranjo, por exemplo: eu sou professora de creche nível I, e eu sei trabalhar com a proposta, então eu vou dispor de um tempo durante a semana para trabalhar com as demais turmas, e enquanto eu trabalhava com a turma da professora de creche nível II, a professora de creche nível II, vai estar tomando conta da minha sala. Foi dessa forma que começou, foi tudo muito doido. Não tem nada acadêmico. É tudo muito doido (PROFESSORA DENA, 2017, grifo nosso).

O forte trabalho desenvolvido com a filosofia nos CEIM's continuou causando expressivo impacto e, por isso, ganhando espaço e visibilidade. Deixou de ser necessário apenas nas creches e pré-escolas, passou a ser desejado também no ensino fundamental, uma necessidade imposta pela chegada das crianças que vinham dos CEIM's e que ofereciam essa experiência reflexiva. O que em certa medida, permitiu o fortalecimento desse movimento na rede.

Aí os meninos começaram a ir para o ensino fundamental, começaram a chegar no ensino fundamental e falavam assim: mas a gente não quer sentar desse jeito, a gente quer sentar daquele jeito assim, assim, e assim... Porque a gente trabalhava em grupo, a gente podia debater. E aí o pessoal do Ensino 
Fundamental começou a ser 'incomodado' por isso (PROFESSORA DENA, 2017, grifo nosso).

Em 2007, a Secretaria Municipal de Educação é convidada pela Universidade Federal do Espírito Santo (UFES) a participar do Encontro de Professores de Filosofia do Espírito Santo (EPFES), apresentando o trabalho de filosofia desenvolvido com as crianças nas escolas públicas de São Mateus. Nesse período, a Secretaria de Educação recebe um novo convite, dessa vez para participar de um evento promovido pela Universidade do Estado do Rio de Janeiro (UERJ), no núcleo ligado ao prof. Walter Omar Kohan. Foi pedido ao município que apresentasse as experiências de Filosofia com crianças que estavam acontecendo. "[...] Nós fomos a UERJ e apresentamos nosso trabalho de formação em um evento que eles promoveram" (Professora DENA, 2017, grifo nosso).

Diferentemente do que tinha acontecido no ano de 2005, com a iniciativa tomada pelos professores de trazerem até São Mateus o CBFC com recursos próprios, em 2007 a Secretaria Municipal de Educação, vendo a crescente repercussão positiva do ensino de filosofia na rede municipal, investe na capacitação de mais 30 professores pelo CBFC.

Já no ano de 2008, a Secretaria de Educação elabora e executa um Curso de Formação Continuada em Filosofia para Crianças, com seis módulos, a saber: I - Formação da comunidade de investigação; II - Elaboração do plano de ensino; III - Filosofia e transdisciplinaridade; IV - Práticas Pedagógicas; V História da filosofia; VI - Avaliação filosófica, perfazendo um total de 120 horas, tendo a participação de 135 professores, que acabou culminando no "I Seminário da História da Filosofia para Crianças".

Também no ano de 2008 é publicada a $2^{a}$ edição revisada e ampliada da "Proposta Pedagógica da Educação Infantil construída a 300 mãos" com as orientações da postura filosófica a ser trabalhada pelos professores.

Em 2011, inicia-se por parte da coordenação da filosofia no município um movimento visando à implantação dessa disciplina na grade curricular dos Centros de Educação Infantil Municipal e das Escolas Municipais de Ensino Fundamental. O Conselho Municipal de Educação recebe da coordenação o 
Programa de ensino de filosofia com crianças, para apreciação e respectiva elaboração de parecer, uma vez que grande parte das escolas municipais já estavam desenvolvendo aulas com essa disciplina.

O movimento passou a ficar tão intenso em torno das práticas filosóficas no cotidiano escolar, que a coordenação de área decidiu realizar quinzenalmente encontros com os educadores a fim de auxiliá-los na composição das aulas a serem dadas. Esses encontros constituem-se como espaço privilegiado para discussão, estudo e partilha das experiências vividas em sala. Acerca disso, nos fala a pedagoga Laura:

Em 2011 nós temos um número de escolas, praticamente todas as escolas da rede admitiram a filosofia, [...] a gente fazia o formato que Cariacica hoje tem, por exemplo: todo professor de filosofia tinha que ter o seu PL [planejamento semanal de aula], em nosso caso era na sexta-feira, todos os professores tinham que vir para gente [se encontrar com a coordenação da filosofia], e a gente fazia o PL juntos a cada quinze dias, montava material para duas semanas, ai vocês iam, tentavam aplicar, traziam as experiências para gente, a gente tinha texto pra ler, pra estudar, e fazia de novo, era assim que funcionava (PEDAGOGA LAURA, 2017, grifo nosso).

Nesse mesmo ano (2011), os professores de filosofia também recebem formação da Secretaria de Educação quanto à intencionalidade da proposta de filosofia com crianças, e sobre as questões metodológicas desse ensino. E, em parceria com a Prefeitura Municipal de São Mateus-ES e o Centro Universitário Norte do Espírito Santo (CEUNES/UFES), Departamento de Educação e Ciências Humanas, foi ofertado, ainda, o Curso de Extensão "Nortes da Filosofia: formação continuada, currículos e cotidianos de professores e professoras de filosofia na Educação Básica da Rede Municipal de São Mateus",

Em 2012, é retomada a formação para os professores de filosofia voltada para práticas metodológicas da Comunidade de Investigação. Juntamente com o "Il Curso de Extensão Nortes da Filosofia - A Filosofia na História: O pensar filosófico do seu nascimento à Idade Média", mantendo a parceria entre a 
Prefeitura de São Mateus e o Centro Universitário Norte do Espírito Santo (CEUNES/UFES), Departamento de Educação e Ciências Humanas.

Nos anos de 2013 e 2014, as questões relativas ao ensino de filosofia com as crianças ficam estagnadas, pois, o então secretário de educação retira o coordenador dessa área específica, não nomeando outro em seu lugar. Como consequência, ficam prejudicados os possíveis avanços que estavam em curso. E naturalmente enfraquecido o espaço até então conquistado dentro da rede em nome desse saber.

Faltou dentro da secretaria uma pessoa que fizesse todo 0 encaminhamento dela [da filosofia], uma pessoa referencial, porque quando nós tivemos dentro da secretaria essa pessoa referencial, ela fluiu, já o tempo em que a pessoa referencial não estava aqui, ela paralisava. Então a coordenação de área dentro da secretaria para área especifica da filosofia é muito importante, porque essa pessoa alimenta os professores nas escolas (PEDAGOGA LÚCIA, 2017, grifo nosso).

Já no ano de 2015, ocorreu Concurso Público Municipal de Provas e Títulos, prevendo 03 (três) vagas para contratação de professores licenciados em filosofia em caráter efetivo. No entanto, no primeiro semestre de 2016 , foram convocados todos os 26 candidatos aprovados, mas nem todos tomaram posse. Alguns dos que assumem, pediram exoneração ainda no primeiro ano de trabalho por motivos diversos: aprovação em outros concursos públicos, questões pessoais, falta de motivação com o trabalho/salário, dificuldade na adaptação ao trabalho com as crianças. A falta de formação específica para atuar com as crianças foi um dos motivos mais alegados pela renúncia ao cargo, tomemos como exemplo o professor Vanderlei:

Eu saí da educação infantil de São Mateus por questão de desmotivação, sendo minhas maiores dificuldades o trabalhar filosofia com as crianças, não consegui falar a linguagem delas e também não tive uma didática adequada para trabalhar com as mesmas (PROFESSOR VANDERLEI, 2017, grifo nosso).

Essa falta de preparo inicial por parte da grande maioria dos professores recém concursados para desenvolverem o trabalho com as crianças e, ao mesmo tempo, a não prestação de formação imediata pela Secretaria Municipal 
de Educação para "socorrer" esses profissionais que se encontravam em situação de "estrangeiridade" na educação com os mais pequeninos, foi um fato bastante generalizado, para ilustrar, vejamos o relato do professor Silas que viveu essa tensão inicial:

O meu primeiro mês no trabalho com crianças da educação infantil foi bastante complicado, a minha primeira experiência foi dura pra caramba. [...] Eu levei um livro para dentro da sala, abri o livro, mas quem disse que eu consegui contar história alguma? Primeiro que eu não sabia como contar história, segundo que eu não consegui nem mesmo fazer com que minha presença fosse notada. As crianças continuaram fazendo o que tinha que fazer e eu não consegui de forma alguma chamar a atenção delas. Então o primeiro mês foi bastante complicado, a começar por essa aula, e depois as outras também não foram muito diferentes. [...] Foi um mês que eu pensei em desistir, em deixar, mas não é fácil a gente lembra que precisa de emprego, que precisa de trabalhar, e afinal de contas, se trata de um trabalho que todo mundo almeja, que é um trabalho no setor público, efetivo, e também, afinal de contas, eu tenho família, filho para criar. Então repensei muito, mas a minha vontade inicial foi realmente de desistir, porque eu achei que não ia conseguir (PROFESSOR SILAS, 2017, grifo nosso).

Um docente do Departamento de Educação do Ceunes, UFES ${ }^{5}$, tendo contato com as dificuldades pelas quais passavam os professores recém concursados no trabalho com as crianças, e objetivando ajudá-los, procurou a Secretaria Municipal de Educação e propôs a realização de encontros com os professores de filosofia da Rede Municipal, visando estabelecer formas de cooperação entre a Educação Básica e a Universidade.

Como resultado dessa iniciativa, em meados do ano de 2016, concretizouse nova parceria entre a Prefeitura Municipal de São Mateus e o Departamento de Educação e Ciências Humanas, do Centro Universitário Norte do Espírito Santo (UFES), oportunizando formação para 60 profissionais da rede, por meio de Formação Continuada em Filosofia para Crianças, realizado nas dependências do CEUNES/UFES.

${ }^{5}$ Trata-se do prof. Jair Miranda de Paiva. 
A formação oportunizou aos professores um ambiente importante para a socialização das experiências e o contato com ideias/conceitos pertinentes ao trabalho junto as crianças. Ajudou a nortear as práticas nas escolas, os exercícios de pensamento no dia a dia da sala de aula, auxiliou efetivamente na composição das ideias e nas ações pedagógicas dos educadores.

Em 2017, prossegue o Curso de Formação Continuada em Filosofia para Crianças no CEUNES/UFES, acontecendo também, em caráter esporádico, encontros formativos promovidos pela recém nomeada Coordenadora da área de Filosofia no município.

Um evento muito importante ocorreu nesse ano, o seminário: "Filosofia com Crianças, Infância do Pensar: movimentos nas escolas públicas de São Mateus", resultado da parceria entre a Prefeitura Municipal de São Mateus, o CEUNES/UFES, através do Mestrado em Ensino na Educação Básica, e o Nefi (Núcleo de Estudos de Filosofias e Infâncias), coordenado pelo prof. Walter Kohan, da Universidade do Estado do Rio de Janeiro (UERJ).

Este seminário proporcionou aos professores de filosofia da rede municipal de São Mateus um movimento de aproximação e troca de experiências acerca do ensino/pesquisa das práticas de filosofia com crianças que ocorrem em nossas escolas e nas de Duque de Caxias, sendo esse primeiro encontro uma oportunidade de fortalecimento de vínculo entre os educadores dos dois Estados, e acima de tudo, entre essas instituições públicas.

Em 2018, registramos dois acontecimentos que, a nosso ver, foram muito importantes para o fazer filosófico com crianças em São Mateus: em primeiro lugar, a realização do SEMFILI (Seminário Internacional educação, filosofias, infâncias, filosofar com infâncias: resistir na escola), evento promovido entre a Universidade Federal do Espírito Santo/CEUNES, com organização e apoio do Mestrado em Ensino na Educação Básica, a Prefeitura Municipal de São Mateus, e a Universidade Estadual do Rio de Janeiro (UERJ), através do Núcleo de Estudos Filosofias e Infâncias, coordenador pelo Prof. Walter Kohan, e a Faculdade Vale do Cricaré. A programação contou com conferências, mesasredondas, oficinas, comunicação de trabalhos de pesquisa e extensão voltados às práticas de ensino e ações de resistências na escola. Este, foi, sem dúvida, 
um momento de troca de experiências, estudos, encontros e formação para docentes da rede municipal de São Mateus, que travaram contato com docentes de vários Estados do país e com palestrantes estrangeiros (infelizmente, um dos palestrantes esperados não pôde comparecer $)^{6}$.

Registramos que, entre 2017-2018, mediante o Pós-doutorado no Programa de Pós-graduação em Educação (PropEd-UERJ), junto ao Nefi (Núcleo de Estudos de Filosofias e Infâncias) sob orientação do Profo Walter Kohan, um docente do Departamento de Educação do Ceunes, UFES ${ }^{7}$, exerceu intensa mediação entre as instituições de São Mateus e a UERJ para que fosse possível realizar o Semfili, acontecimento importante, segundo nossa concepção e experiência. Deve-se mencionar, ainda, a generosa disponibilidade e interesse do Profo Kohan, filósofo e autor de renome mundial, em se dispor a contribuir com seu nome, sua presença e prestígio para o evento, bem como se aproximar de modo mais intenso dos fazeres filosóficos com crianças desenvolvidos em São Mateus.

O segundo acontecimento, que reputamos fundamental para esse trajeto do ensino de filosofia com crianças em São Mateus, consistiu na aprovação do parecer sobre 'O Ensino de Filosofia Para e Com Crianças em São Mateus'8, que respondeu ao OF/PMSM/SME/N 246/2013, de 09 de setembro de 2013, obtendo, após intensos debates, parecer favorável à prática da disciplina como

\footnotetext{
${ }^{6}$ Dentre os convidados citamos: Professor Dr. Walter Kohan (UERJ), Profa Dra. Laura Viviana Agratti (Universidade Nacional de La Plata), Prof ${ }^{a}$ Dra. Paula Ramos de Oliveira (Unesp), Prof ${ }^{a}$ Dra. Maria Reilta Dantas Cirino (UERN), Prof ${ }^{a}$ Dra. Carmem Sanches Sampaio (UNIRIO), Prof ${ }^{a}$ Dra. Paula Linhares (UFABC), Profa Dra. Vanise de Cássia de Araújo Dutra Gomes (Nefi-UERJ e Prefeitura de Caxias), Profa Ma. Edna Olímpia da Cunha (Nefi-UERJ e Prefeitura de Caixas), Doutoranda Profa Neila Ruiz Alfonzo (Nefi-UERJ e Colégio Pedro II, RJ e), dentre outros.

7 Trata-se do prof. Jair M. de Paiva.

${ }^{8}$ Ao utilizamos o termo 'Filosofia para e com Crianças' fazemos menção a dois movimentos teóricos, que a nosso ver, dialogam e se complementam. O termo 'Filosofia para Crianças' ganha sentido com a iniciativa de Matthew Lipman em exercitar práticas filosóficas para além dos espaços acadêmicos, dando novo sentido ao fazer e produzir filosofia, afirmando através de seu movimento que o filosofar não se restringe ou se limita a eruditos, mas é um saber que se destina a todos, por isso, Lipman objetivou levar a filosofia para as crianças. Já o termo 'Filosofia com Crianças' se refere ao pensamento de Walter Omar Kohan, no sentido de que as experiências de pensamentos acontecem num movimento coletivo, de diálogo, de amizade, de cumplicidade, ou seja, nesse encontro entre adultos e crianças. Com base nesses entendimentos, adotamos na construção do parecer de filosofia a junção de ambos os termos, a saber: 'Filosofia para e com Crianças'.
} 
parte diversificada ${ }^{9}$ do currículo desenvolvido na educação municipal, votado e aprovado em 30/08/2018. Apesar da aprovação do parecer, que consideramos importante avanço, a disciplina de filosofia ainda carece de uma resolução que possa nortear sua organização e prática no cotidiano escolar.

Em 2019, prosseguem, em caráter esporádico, encontros formativos promovidos pela coordenação de área da disciplina de filosofia no município.

Em 2020, mesmo com a suspensão das aulas na rede municipal de educação de São Mateus, devido ao isolamento social (quarentena), provocado pela pandemia de Covid-19, prosseguem os encontros formativos promovidos pela coordenação de área da disciplina de filosofia no município, por meio de recursos de videoconferência.

Espera-se para o ano de 2021 o prosseguimento da afirmação do ensino de filosofia na educação municipal, ampliando a credibilidade e espaço em relação a esse saber/fazer, gerando junto aos alunos condições de 'alçar vôos' na construção de uma escola pública, popular e igualitária, de tempo livre, criadora de pensamentos infantis.

Enfim, esse processo de inserção da filosofia na rede municipal de São Mateus não é algo fácil de ser contado, porque não se trata de uma história linear, mas de movimentos de vidas. São histórias cheias de pontos e contrapontos, acontecimentos e devires, agenciamentos e movimentos de resistência. Nessa dinâmica movediça, paradoxal e assombrosa de narrar vidas, acontecimentos, conquistas e retrocessos, constatamos a vivência da infância do narrador ao contar histórias. Porque ao contá-las, pôde também vivê-las, senti-las vibrar.

\section{0 sentido da prática: refletindo sobre o exercício do filosofar}

Tomando como orientação a exposição histórica da filosofia com crianças em São Mateus, indicaremos algumas pistas reflexivas que podem nos ajudar a pensar esse processo em construção.

\footnotetext{
${ }^{9}$ LDB - Art. 26. Os currículos da educação infantil, do ensino fundamental e do ensino médio devem ter uma base nacional comum, a ser complementada, em cada sistema de ensino e em cada estabelecimento escolar, por uma parte diversificada, exigida pelas características regionais e locais da sociedade, da cultura, da economia e dos educandos.
} 
Entendemos que a proposta educativa exercitada na rede pública municipal não é, ou pretende ser, um discurso ou uma prática 'salvacionista' da educação, pelo contrário. Esse conhecimento soma-se aos outros saberes praticados, compondo juntos caminhos que permitam aos educandos uma formação que busca promover a igualdade de oportunidades educacionais entre as crianças de diferentes classes sociais no que se refere ao acesso aos bens culturais e às possibilidades de vivência da infância.

Acreditamos que a potência da reflexão filosófica, mesclada aos outros saberes produzidos no ambiente escolar, podem possibilitar às crianças 0 conhecimento de si mesmas, dos outros e do mundo, por meio da ampliação das experiências sensoriais, expressivas, corporais, linguísticas, entre outras, com o incentivo à curiosidade, à exploração, à imaginação, à indagação e à criatividade, elementos fundamentais para a promoção da autonomia.

É importante ressaltar que a prática da reflexão não é exclusiva ou limitada ao dito 'filósofo' ou às pessoas graduadas em filosofia, como nos indica Deleuze (2010) em sua obra “O que é filosofia?", e nos mostra Lipman (1990), com o seu programa de filosofia para crianças, mas é um conhecimento disponível a todos que se propõem a navegar pelos campos das ideias de maneira autêntica, exposta, curiosa e corajosa, adjetivos evidentes nas crianças.

$\mathrm{Se}$, por um lado, todos podemos exercer a reflexão, por outro, emerge uma questão fundamental para a compreensão do exercício da filosofia nas escolas municipais, a saber: qual a peculiaridade da filosofia?

Em nosso modesto caminhar, percebemos que a singularidade da filosofia está no fato de ela ser revolucionária, e o que permite a ela esse adjetivo, é sua condição de não hierarquizar os pensamentos, sendo todos os pensamentos igualmente importantes, como afirma Deleuze (2010). Ela possibilita espaço para o diálogo entre iguais, no sentido de permitir a todos o mesmo direito à palavra.

Tal proposta educativa, em síntese: produz condição de igualdade, como já indicava Rancière (2013), em sua obra 'O mestre ignorante'. Ou seja, a preciosidade da filosofia se encontra justamente aí: na capacidade de promover a igualdade numa sociedade historicamente desigual, oportunizando espaço de pensamento e diálogo a todos, sem distinção de nenhuma natureza. 
Assim, compreendemos que a experiência do filosofar não se esgota em apenas entender, analisar, interpretar o mundo, os fatos, as relações, mas, sobretudo, em criar novos mundos, outros fatos, diferentes relações... Criando novas organizações no pensamento, capazes de transformar, de ressignificar, de "desengaiolar" as ideias.

O objetivo da aula de filosofia, a nosso ver, e em concordância com Deleuze (2010), está em criar condições (físicas, espaciais, temporais, metodológicas, dialógicas, organizacionais...) para que a criação ocorra, ou seja, será potencializar uma pedagogia da criação, da invenção, da pergunta.

Nesse horizonte, caberá ao professor aprofundar questões que emergem junto às crianças no decorrer da vida escolar, pois travar contato com questões complexas, sensíveis, dogmáticas, há tempos cristalizadas exige condições de tempo e espaço, e muitas vezes também exigem abordagens múltiplas e, principalmente, perguntas que possibilitem ampliar a discussão acerca de temas relevantes para a construção da autonomia do pensamento, pois:

[...] se queremos propiciar a experiência da filosofia à escola, é preciso que crianças e professores perguntem e se perguntem. Que eles traçem seus problemas, inventem seus sentidos e sigam uma linha problematizadora. Se eles não se colocarem em questão, se o seu perguntar não se originar na sua própria inquietação, nos signos que lhe são significativos; se ele não se prolongar no seu próprio pensar então estarão apenas mimetizando uma interrogação externa [...] (KOHAN, 2011, p. 104, grifo nosso).

$\mathrm{O}$ ato de perguntar é ponto de partida no exercício do pensamento, pois a pergunta é o que abre, amplia o diálogo, aprofunda a reflexão. Por isso, é fundamental colocarmos, desde o início, redobrada atenção em nossas perguntas, afinal, elas são a chave para a transformação de nós mesmos.

Nessa direção, percebe-se que a experiência do filosofar tem a ver com vivência, com um movimento de colocar-se em questão, num diálogo aberto, afetuoso e solidário. E o exercício junto às crianças é atravessado de perguntas, curiosidades e brincadeiras, em que questões são colocadas, às vezes de forma inesperada, de modo simples, e provocador. Filosofar com crianças é estar 
aberto ao novo, ao imprevisível, num movimento único e irrepetível, uma vez que:

Entendemos a prática da filosofia como uma experiência intersubjetiva do pensar. A experiência, não a técnica, está na base de um tal pensar. Quando se procura reproduzir ou generalizar uma experiência, ela se torna experimento, espelho do mesmo. Ao contrário, a filosofia, como experiência, não pode normalizar-se, uniformizar-se, estandardizar-se. Ninguém pode fazer experiência por outro, ninguém pode pensar por outro, ninguém pode filosofar por outro [...] (KOHAN, 2011, p. 108, grifo nosso).

Como se vê, a experiência filosófica é intransferível, é um convite àqueles que desejam se lançar ao desconhecido. Somos convidados a lançarmo-nos numa aventura de autotransformação, sem objetivo de colocar o outro em questão ou em teste, mas em voltar-se sobre nós mesmos, por meio da pergunta transformadora. "Em última instância, uma educação transformadora é aquela que transforma o que pensamos, o que somos, o que fazemos numa relação aberta com a novidade dos novos" (KOHAN, 2011, p. 112).

Enfim, filosofar com crianças não quer transformar a criança naquilo que ela não é, nem em transformar a filosofia em instrumento de cerceamento do pensamento da infância. Esse movimento tem a ver com abertura ao novo. Novidade que a criança carrega e que a filosofia se nutre. Uma interação entre adultos e crianças, através da abertura ao diálogo fraterno e solidário.

\section{Considerações finais}

Exercitar a filosofia com criança é sempre um desafio. Não há receita, nem fórmula mágica de como fazer. O que há, em última instância, é um convite a colocar-se nesse processo de construção de sentidos. Não sendo uma construção de sentidos para o outro, mas para si mesmo.

Nesta perspectiva, compreendemos que as práticas de filosofia com crianças nas escolas públicas de São Mateus (evidenciadas nas narrativas apresentadas), mostram desafios, aprendizados, (des)encontros, trocas e, acima de tudo, transformações. Demonstrando que, apesar dos muitos entraves 
e dificuldades, sempre desejou-se educar-se pela e na infância, mediados pela e na filosofia.

É evidente que a relação entre adultos e crianças é um espaço fértil de criação e troca de saberes, capaz de descortinar horizontes ainda não vislumbrados. Sendo possível também observar que a filosofia e a infância são guardiãs da novidade, que uma não deve dominar a outra, mas trabalhar em cumplicidade, cooperando para que a força da pergunta continue promovendo experiências transformadoras no agir e no pensar, potencializando a amizade, a alegria e o desejo dem aprender uns com os outros.

\section{Referências}

BARROS, Manoel de. Livro sobre nada. 8. ed. Rio de Janeiro: Record, 2000.

$\mathrm{BLOCH}$, Marc. Apologia da história ou o ofício de historiador. Rio de Janeiro: Zahar, 2001.

BRASIL. Ministério de Educação e Cultura. LDB - Lei n 9394/96, de 20 de dezembro de 1996. Estabelece as diretrizes e bases da Educação Nacional. Brasília: MEC, 1996.

CARDOSO, Heloisa Helena Pacheco. Narradores de Javé: histórias, imagens, percepções. Fênix - Revista de História e Estudos Culturais Abri/ Mai/ Jun. de 2008 Vol. 5 Ano V n 2.

CERLETTI, Alejandro. O ensino de filosofia como problema filosófico. Belo Horizonte: Ed. Autêntica, 2009.

CERTEAU, Michel de. A invenção do cotidiano: artes de fazer. Petrópolis: Vozes, 1998.

CUNHA, Mauro Britto. Em busca da infância: experiências filosóficas com crianças numa escola pública municipal de São Mateus, ES. 2018. $180 \mathrm{f}$. Dissertação (Mestrado em Ensino na Educação Básica) - Universidade Federal do Espírito Santo, São Mateus/ES.

DELEUZE, Gilles; GUATTARI, Félix. O que é filosofia? 3. ed. São Paulo: Editora 34, 2010.

JESUS, José Adilson Vieira de. Sophia mora ao lado: Avanços e Entraves do Ensino de Filosofia na Rede Municipal de São Mateus, ES. 2018. 128 f. Dissertação (Mestrado em Gestão da Educação) - Faculdade Vale do Cricaré, São Mateus, ES.

KOHAN, Walter Omar. Infância, estrangeiridade e ignorância: ensaios de filosofia e educação. Belo horizonte: Autêntica, 2007. 
Infância. Entre educação e filosofia. $2^{\mathrm{a}}$.ed. (Coleção Educação: experiência e sentido, 3). Belo horizonte: Autêntica, 2011.

LIPMAN, Matthew. A filosofia vai à escola. Tradução de Maria Elice de Brzezinski Prestes e Lucia Maria Silva Kremer. São Paulo: Summus, 1990.

RANCIĖRE, Jacques. O mestre ignorante: cinco lições sobre a emancipação intelectual. 3.ed. Belo Horizonte: Autêntica, 2013.

SAVIANI, Dermeval. Educação: do senso comum à consciência filosófica. 19a.ed. São Paulo: Autores Associados, 2013.

\section{Sobre os autores}

\section{Mauro Britto Cunha}

Email: maurobrittoc@gmail.com

Mestre em Ensino na Educação Básica pelo Programa de Pós-graduação em Ensino na Educação Básica, UFES/CEUNES (2018). Graduado em Filosofia (Faculdade Salesiana de Vitória, ES). Professor da Educação Básica na Secretaria Municipal de São Mateus, ES.

\section{Jair Miranda de Paiva}

Email: jmipaiva@gmail.com

Doutor em Educação (UFES, 2009). Pós-doutor em Educação (UERJ, 2018). Docente da Universidade Federal do Espírito Santo, São Mateus, Departamento de Educação e Ciências Humanas e do Programa de Pós-graduação em Ensino na Educação Básica, UFES/CEUNES. 